could contribute significantly to our understanding and management of carcinoma of the gastrointestinal tract.

We thank the physicians and surgeons of the United Birmingham Hospitals, particularly Mr. V. S. Brookes and Mr. J. Alexander Williams, for allowing us to study patients under their care.

\section{References}

Allan, R. N., et al. (1972). Gastroenterology, 62, 1227.

Booth, S. N. et al. (1972). Unpublished.

Booth, S. N., et al. (1973). Gut, 14, 794 .

Currie, G. A., and Basham, C. (1972). British fournal of Cancer, 26, 427.

Davies, R. J., Vernon, M., and Croft, D. N. (1974). Lancet, 1, 279.
Dhar, P., et al. (1972). Fournal of the American Medical Association, 221, 31. Egan, M. L., et al. (1972). Immunochemistry, 9, 289.

Embleton, M. J. (1973). British fournal of Cancer, 28, Suppl. 1, 142.

Flanagan, L, and Foster, J. H. (1967). American fournal of Surgery, 113, 551. Glanagan, L., and Foster, J. H. (1967). American fournal of Surgery, 113, Obstetrics, 114, 438,

Holyoke, D., Reynoso, G., and Chu, T. M. (1972). Annals of Surgery, 176, 559.

Kim, U., and Carruthers, C. (1972). Proceedings of the American Association of Cancer Research, 13, 69.

Laurence, D. J. R., et al. (1972). British Medical fournal, 3, 605.

Moertel, C. G., (1973). In Cancer Medicine. ed. J. F. Holland and E. Frei, p. 1616. Philadelphia, Lea and Febiger.

Sjogren, H. O., et al. (1971). Proceedings of the National Academy of Science, 68, 1372 .

Sorokin, J. J., et al. (1974). Fournal of the American Medical Association, 228, 49 .

Thomson, D. M., et al. (1969). Proceedings of the National Academy of Science, 64, 161 .

\title{
Action of Different Bran Preparations on Colonic Function
}

\author{
W. O. KIRWAN, \\ A. N. SMITH, \\ A. A. MCCONNELL, \\ W. D. MITCHELL, \\ M. A. EASTWOOD
}

British Medical fournal, 1974, 4, 187-189

\section{Summary}

Two different types of commercially available bran were studied. One of these was composed of flake-like particles (coarse bran) whereas the other had smaller, finer particles with a floury component (fine bran). The effectiveness of the two preparations in lowering intraluminal pressure and decreasing transit time in patients with constipation and diverticular disease was assessed. Only coarse bran promoted changes at the dose used. The physical properties of the brans were examined in an effort to explain their differing effects. It is concluded that water-holding capacity, upon which the beneficial effect of bran may depend, is a function of particle size. The greater water-holding capacity of coarse bran makes it preferable for the treatment of colonic disorders.

\section{Introduction}

The value of bran in the symptomatic treatment of diverticular disease (Painter et al., 1972) and constipation (Harvey et al., 1973) has been established. It has been shown that intraluminal colonic pressure is abnormally high in diverticular disease and constipation (Arfwidsson and Kock, 1964; Painter and Truelove, 1964). Gastrointestinal transit time is prolonged in diverticular disease (Findlay et al., 1974) and in constipation (Kirwan and Smith, 1974), and it has been established that bran lowers intraluminal pressure and shortens the transit time in such patients (Findlay et al., 1974).

This study was prompted by the observation that two types of bran differed in their appearance, in their clinical efficacy, and in their ability to lower intraluminal pressure and reduce transit time. Physical characteristics of the two brans were examined in an effort to explain their differing effect.

Department of Clinical Surgery and Wolfson Gastrointestinal Laboratories, University of Edinburgh, Western General Hospital, Edinburgh

W. O. KIRWAN, M.B., F.R.C.S., Research Fellow

A. N. SMITH, M.D., F.R.C.S., Reader in Clinical Surgery

A. A. McCONNELL, B.SC., PH.D., Research Fellow

A. A. MCCONNELL, B.SC., PH.D., Research Fellow

M. A. EASTWOOD, M.SC., F.R.C.P., Consultant Gastroenterologist

\section{Methods}

Two groups of patients were studied before and after taking bran $10 \mathrm{~g}$ twice daily for four weeks. One group took a coarse preparation of bran (Prewitt's) of which none of the particles or flakes passed through a sieve of $1-\mathrm{mm}$ diameter and the other group took a fine preparation (Allinson's) which entirely passed through a sieve of $1-\mathrm{mm}$ diameter pore size. Fine bran also contained appreciable amounts of endosperm (flour).

Coarse-bran Group.- This group consisted of nine patients with radiologically proved diverticular disease. Colonic motility before taking bran was measured using open-ended tubes (Smith et al., 1971) and gastrointestinal transit time was measured using radio-opaque pellets (Hinton et al., 1969). These investigations were repeated after four weeks of treatment with coarse bran $10 \mathrm{~g}$ twice daily.

Fine-bran Group.-This group consisted of five patients. Three had radiologically proved diverticular disease. Two patients complained of difficult and infrequent bowel movements and occasional abdominal pain. After investigations which failed to show any organic abnormality a diagnosis of constipation was made. Colonic motility before bran was measured using the same method as in the former group. Gastrointestinal transit time was measured using a radioisotope capsule (Kirwan and Smith, 1974). These investigations were repeated after four weeks of treatment with fine bran $10 \mathrm{~g}$ twice daily, and in four patients who consented to a third study the tests were again repeated after switching to the coarse bran for a further four weeks.

\section{PHYSICAL CHARACTERISTICS OF BRANS}

To determine the physical characteristics of the brans both were shaken for 90 minutes in test sieves and the flour from each bran which passed through the mesh was weighed. The acid detergent fibre, which measures the cellulose and lignin content of the brans, was determined by the method of van Soest (1963).

The water-holding capacity of a fibre is a function of the ability of the fibre to retain water and is signified by the amount of water held by $1 \mathrm{~g}$ of the dried material (McConnell et al., 1974). It was measured for each bran by adding a known quantity of bran to a weighed tube, excess water then being added and the mixture being left to equilibrate for 24 hours. The tube was then centrifuged at $14,000 \mathrm{~g}$ for one hour and the supernatant was then removed leaving the bran with its associated water. The result was expressed as grammes of water per gramme of bran. 
The cation exchange capacity was determined by the method of $\mathrm{pH}$ titration (Hefferlich, 1962). The bran was saturated with $\mathrm{H}^{+}$ions, washed, and its capacity to exchange these $\mathrm{H}^{+}$ions for $\mathrm{Na}^{+}$ions was then determined by titration with $\mathrm{NaOH}$. The result was expressed as $\mathrm{mEq}$ of $\mathrm{Na}^{+}$per gramme of bran.

The pore size distribution of the two brans was measured by a mercury penetration porosimeter (Micromeritics, Model 900, Coulter Electronics Ltd.). This technique determines the quantity of mercury forced into the pores of the material under investigation and then the quantity expelled at various decreasing pressures. At low pressures (less than $50 \mathrm{lb} / \mathrm{in}^{2}\left(3.5 \mathrm{Kg} / \mathrm{cm}^{2}\right)$ ) some of the mercury is considered as entering "void spaces" among the particles while at higher pressures it penetrates pores within the particles themselves.

\section{Results}

Coarse-bran Patients.-The basal motility index (mean \pm S.E.) was lowered from $892 \cdot 8 \pm 196$ to $648 \cdot 7 \pm 339$ but the change was not statistically significant. The motility index after food was lowered significantly from $1,513 \cdot 2 \pm 456$ to $446 \cdot 1 \pm 130$ ( $\mathrm{P}<$ 0.01 ), and that after neostigmine was significantly lowered from $2,120 \cdot 0 \pm 405$ to $1,216 \cdot 8 \pm 398(P<0.01)$. The gastrointestinal transit time was significantly lowered from $93.4 \pm 13 \cdot 8$ to $57 \cdot 9 \pm$ 8.0 hours $(P<0.01)$.

Fine-bran Patients.-All the motility indices (Mean \pm S.E.) increased after bran. The basal, post-food, and post-neostigmine motility indices increased from $1,181 \pm 489$ to $1,269 \pm 468$, $1,429 \pm 405$ to $2,534 \pm 653$, and $4,075 \pm 873$ to $4,661 \pm 410$ respectively. The gastrointestinal transit time fell from $98 \pm 32$ hours to $86 \pm 34$ hours. These changes were not statistically significant.

Coarse versus Fine Bran.-The change in motility index produced by coarse bran was compared with that produced by fine bran. There was a significant difference between the effect of the two brans in the phase after food $(P<0.005)$ and in the phase after neostigmine $(P<0.05)$.

Coarse Bran after Fine Bran.-In four patients first given fine bran who agreed to change to coarse bran and undergo a third series of tests the mean transit time ( $t$ S.E.) after four weeks of coarse bran was lowered from $96 \pm 43$ hours to $51 \pm 26$ hours, the basal motility index was lowered from $1,202 \pm 596$ to $303 \pm 168$, the motility index after food was lowered from $2,369 \pm 811$ to $1,459 \pm 637$, and the post-neostigmine motility index was lowered from $4,726 \pm 522$ to $2,746 \pm 749(\mathrm{P}<0.05)$. The overall motility result in 13 patients treated by coarse bran is shown in table I. The basal motility fell from $878 \pm 192$ to $335 \pm 108(P<0.01)$, the motility after food from $1,812 \pm 391$ to $733 \pm 237(\mathrm{P}<0.01)$, and the post-neostigmine motility from $2,758 \pm 514$ to $1,545 \pm 355(P<0 \cdot 01)$.

TABLE I-Mean Motility Indices ( \pm S.E.) in 13 Patients with Diverticular Disease before and after Four Weeks of Treatment with Coarse Bran

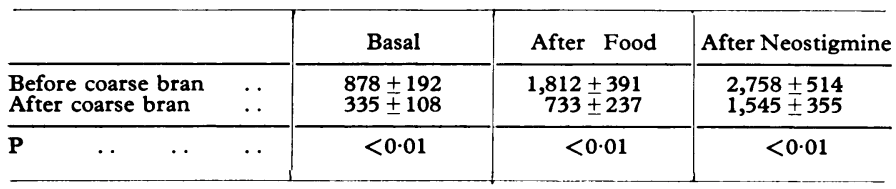

\section{PROPERTIES OF BRANS}

The moisture contents of coarse and fine bran were $9.6 \%$ and $11.1 \%$ respectively; the protein contents were $14.0 \%$ and $13.3 \%$ respectively.

The amount of each bran passing through different mesh aperture sizes is shown in table II. Much more of the second bran than the first bran passed through the small aperture mesh, thus confirming that it had many more small particles.

\begin{tabular}{|c|c|c|c|}
\hline \multirow[b]{2}{*}{ Mesh No. } & \multirow{2}{*}{$\underset{(\mu \mathrm{m})}{\text { Aperture Size }}$} & \multicolumn{2}{|c|}{${ }_{o}^{\circ}$ Filtering through Mesh } \\
\hline & & Coarse Bran & Fine Bran \\
\hline $\begin{array}{r}>14 \\
22 \\
44 \\
60 \\
<60\end{array}$ & $\begin{array}{r}1,200 \\
710 \\
355 \\
250 \\
<250\end{array}$ & $\begin{array}{r}69.3 \\
27.3 \\
2.5 \\
0.5 \\
0.5\end{array}$ & $\begin{array}{r}5 \cdot 6 \\
22 \cdot 1 \\
39 \cdot 0 \\
21 \cdot 0 \\
12 \cdot 3\end{array}$ \\
\hline & Total & 100 & 100 \\
\hline
\end{tabular}

The water-holding capacities of coarse and fine bran were $6.15 \mathrm{~g}$ and $2.36 \mathrm{~g}$ of water per $\mathrm{g}$ of bran respectively. The respective acid detergent fibre contents were $15.11 \%$ and $9.65 \%$, the lignin contents $4.1 \%$ and $2.63 \%$, and the cation exchange capacities $1.2 \mathrm{mEq}$ and $0.7 \mathrm{mEq}$ per gramme.

After milling both brans to a particle size of $1 \mathrm{~mm}$ the waterholding capacity of the first bran became $3.54 \mathrm{~g} / \mathrm{g}$ and the water-holding capacity of the second bran became $2 \cdot 16 \mathrm{~g} / \mathrm{g}$. After milling the cation exchange capacities became respectively 0.4 and $0.7 \mathrm{mEq} \mathrm{NaOH}$ per $\mathrm{g}$ of bran.

When both brans were examined for pore size distribution there was marked intrusion between 1 and $50 \mathrm{lb} / \mathrm{in}^{2}(0.07$ and $3.5 \mathrm{~kg} / \mathrm{cm}^{2}$ ) atmospheric, which was probably related to uptake of mercury into the interparticle space. This was measurably greater for coarse bran than fine bran. The computed pore size, however, was the same for the two brans.

\section{Discussion}

The marked difference in the effect of the two brans on bowel function was unexpected. Fine bran failed completely at a dosage of $20 \mathrm{~g} /$ day to produce significant changes in the colonic motility index or the gastrointestinal transit time. Substitution of coarse for fine bran, however, greatly reduced transit time and the intraluminal pressure in four weeks. Because of its ineffectiveness fewer patients were treated with fine bran than coarse bran.

The beneficial effect of bran is probably due to its waterholding effect, giving rise to a soft bulky stool which is easily passed. The water-holding capacity of fibre depends on the type of plant from which the fibre is derived (McConnell et al., 1974). Water is associated with fibre in various phasessurface water, entrapped or interstitial water, and free water (Findlay et al., 1974). The water-holding capacity of brans must be influenced by the capacity of the interstices to hold water. With large particle size the intra- or interparticulate spaces should be larger and become more available for the carriage of interstitial water. An analogy with sponges of different sizes and with different-sized pores is appropriate. Our observations suggest that bran with coarse particles holds more water and thus provides more bulk in the stool than does bran with finer particles. The change in motility index resulting from bran may depend on the bulk provided since intraluminal pressure depends not only on force exerted by muscle but also upon diameter of the bowel lumen and the viscosity of its contents. Coarse bran was found to hold much more water than fine bran ( $6.15 \mathrm{~g}$ and $2.36 \mathrm{~g}$ respectively) and it seems likely that the low water-holding capacity of the fine bran accounts for its failure to improve colonic function. Milling coarse bran to a particle size of $1 \mathrm{~mm}$ (thus considerably lowering its particle size) almost halved its water-holding capacity from $6 \cdot 15 \mathrm{~g}$ to $3.54 \mathrm{~g}$ of water per $g$ of bran. Milling fine bran to a similar size had little effect on water-holding capacity $(2 \cdot 36 \mathrm{~g}$ to $2 \cdot 15 \mathrm{~g}$ per $\mathrm{g})$. These results indicate that particle size is of fundamental importance in determining the water holding capacity and clinical efficacy of bran.

The coarse bran contained more acid detergent fibre than the fine bran. Coarse bran also contained more lignin than fine bran. The cation exchange capacity of coarse bran was greater than that of fine bran. All of these differences were less marked than 
those in the water-holding capacity. Since changing the particle size greatly alters the water-holding capacity but does not alter the fibre or lignin content it seems that particle size is more important than fibre or lignin content.

The coarse-bran preparation was closer to pure bran, which is the material left after the flour has been separated from the grain. The fine-bran appeared to containan appreciable amount of what seemed to be flour (endosperm). The difference between the two preparations is a reflection of the degree of milling or the stage of extraction at which the brans were obtained.

In the treatment by bran of diverticular disease and constipation it seems that a useful criterion for success is the amount of alteration of the stool weight (Burkitt et al., 1972). Theoretically increasing the stool weight should be achieved by increasing the dietary intake of fibre from any plant source, from vegetables and fruits as well as bran, so long as there is a substantial waterholding capacity as has been shown, for example, in carrots, apples, oranges, brussels sprouts, etc. (McConnell et al., 1974). While the water-holding capacity of bran is in comparison a modest one the fact that it is $85 \%$ dry material magnifies its importance. It is easier for most people to take $20 \mathrm{~g}$ of bran as a source of fibre than the comparable amount of fibre from other sources (200-300g raw material).

It is possible that if fine bran were given in a larger dose there would be sufficient large particles and water-holding capacity for it to improve bowel function also. This form of bran, however, contains considerable amounts of absorbable carbohydrate (two of our female patients complained of having put on $4 \mathrm{lb}$ and $5 \mathrm{lb}$ in weight over four weeks) and increasing the dose might result in unacceptable weight gain.

This work was done during the tenure of Scottish Endowments Ho:pitals Research Trust Grant No. 418 and with support from the British Nutrition Foundation.

We thank Miss E. G. P. Drummond for skilled technical help and Dr. J. B. Hutchinson, Flour Milling and Baking Research Association, Chorleywood, for advice and help.

Requests for reprints should be sent to A.N.S.

\section{References}

Arfwidsson, S., and Kock, N. G. (1964). Acta Chirurgica Scandinavica, Suppl. No. 342, p. 1

Burkitt, D. P., Walker, A. R. P., and Painter, N. S. (1972). Lancet, 2, 1408 Findlay, J. M., et al. (1974). Lancet, 1, 146.

Harvey, R. F., Pomare E. W. and Heaton, K. W. (1973). Lancet, 1278. Helfferich, F.' (1962). Ion Exchange, p. 92. New York, McGraw-Hill.

Helferich, . (1962). Ion Exchange, p. 92. New A. C. (1969). Gut, 10, 842. Kirwan, W. O., and Smith, A. N. (1974). Scandinavian fournal of Gastroenterology. In press.

McConnell, A. A., Eastwood, M. A., and Mitchell, W. D. (1974). Fournal of the Science of Food and Agriculture. In press.

Painter, N. S., Almeida, A. Z., and Colebourne, K. W. (1972). British Medical fournal, 2, 137.

Painter, N. S., and Truelove, S. C. (1964). Gut, 5, 201.

Smith, A. N., Giannakos, V., and Clarke, S. (1971). Fournal of the Royal College of Surgeons, Edinburgh, 16, 276.

van Soest, P. J. (1963). Fournal of the Association of Official Agricultural Chemists, 46, 829.

\title{
Lack of Harmful Effect of Oats on Small-intestinal Mucosa in Coeliac Disease
}

\author{
A. S. DISSANAYAKE, S. C. TRUELOVE, R. WHITEHEAD
}

British Medical fournal, 1974, 4, 189-191

\section{Summary}

It is well established that wheat, rye, and barley are harmful to patients with coeliac disease, but the effect of oats remains in doubt. Four patients with coeliac disease, who had shown complete mucosal recovery after prolonged treatment with a strict gluten-free diet, volunteered to consume oats in addition to their gluten-free diet for a period of one month and were studied by jejunal biopsy before and after the experimental period. The patients remained entirely symptom-free and, more important, the jejunal mucosa was undamaged as judged by appearances under dissecting and light microscopes, quantitative histological studies, and disaccharidase content. It is concluded that oats are harmless to coeliac subjects and can be included in a gluten-free diet.

\section{Introduction}

It is well established that wheat, rye, and barley are damaging to the small-intestinal mucosa of coeliac subjects, while

Nuffield Department of Clinical Medicine, and Department of Morbid Anatomy, Radclifie Infirmary, Oxford

A. S. DISSANAYAKE, M.B., D.PHIL., Research Assistant S. C. TRUELOVE, M.D., F.R.C.P., Physician

R. WHITEHEAD, M.D., M.R.C.PATH., Consultant Pathologist maize and rice are harmless. The effect of oats remains controversial (Anderson et al., 1972).

We felt, therefore, that a study of the histological responses and disaccharidase levels in jejunal biopsy specimens from coeliac patients who had responded well to a gluten-free diet and who were then fed on oats would solve the problem.

\section{Patients and Methods}

Four patients volunteered to take part in this study. In all cases their coeliac disease had been diagnosed on the basis of their clinical presentation and the finding of a flat mucosa on jejunal biopsy together with severe depression of all three disaccharidases. They rapidly became symptom free on a strict gluten-free diet and the diagnosis was confirmed by a repeat jejunal biopsy after several months which showed that the morphological appearances and disaccharidases had become normal. At the time of entry into this study all four patients had been on a strict gluten-free diet for at least one year.

These patients were assessed clinically and had routine blood investigations and a jejunal biopsy at the start of the study. They were given porridge oats to be taken $40-60 \mathrm{~g} /$ day as porridge, oat cakes, or "flap-jacks" and also instructed to continue on an otherwise strict gluten-free diet. This dose of oats was selected because it was felt that larger daily doses are not easily tolerated by many normal people. Furthermore, from our recent follow-up study of coeliac patients it is clear that even small amounts of wheat gluten produce pronounced 